\title{
Varicella-Related Hospitalizations Among Immunocompetent and Immunocompromised Children in Pre-Vaccine Era: A Tertiary Care Center Experience in Turkey
}

\author{
(1) Özlem Akgün Doğan, (1) Seda Topçu, • Naciye Gönül Tanır \\ University of Health and Sciences, Dr. Sami Ulus Maternity and Children's Training and Research Hospital, Clinic of Pediatrics, Ankara, Turkey
}

\begin{abstract}
Aim: Although varicella is a common, contagious, self-limited childhood disease, it can cause significant long-term sequelae and mortality in both immunocompetent and immunocompromised children. The aim of the present study is to identify and review varicella-related hospitalizations, admissions and complications of primary varicella infection among immunocompetent and immunocompromised children of a large unselected local population in a governmental institution.

Materials and Methods: Demographic aspects, clinical features, microbiological findings, complications, managements and outcome of the patients hospitalized for varicella were analyzed retrospectively.

Results: Among 100 such children, 66 were immunocompetent and 34 were immunocompromised. Secondary bacterial infection was the most common complication in both groups. The second most common complication in the immunocompetent group was neurological complications (21\%) followed by varicella-zoster virus (VZV) pneumonia (2\%). In the immunocompromised group neurological complications and VZV pneumonia were not observed. Hematological complications were seen in $5 \%$ of the immunocompetent patients and $6 \%$ of the immunocompromised patients. Mortality was seen in $2 \%$ in the study group, one patient in the immunocompetent and one in the immunocompromised group.

Conclusion: Despite a common perception of varicella infection being highly contagious but harmless, complications requiring hospitalization are frequent, potentially serious and costly even in healthy children. Since varicella virus vaccine prevents most of the morbidity and mortality caused by primary varicella in children, prevention rather than the treatment will be the optimal approach.

Keywords: Varicella, complication, healthy, immunocompromised, child
\end{abstract}

\section{Introduction}

Varicella is a common, contagious disease caused by primary varicella-zoster virus (VZV) infection, and it is usually a benign and self-limited childhood disease in healthy children $(1,2)$. The disease course is usually more severe in immunocompromised children. However, mosthospitalizations for varicella are of previously healthy children. Varicella can cause significant long-term sequelae and mortality in both immunocompetent and immunocompromised children $(1,3)$. The American Academy of Pediatrics and Advisory Committee on Immunization recommends varicella vaccine to prevent most of the morbidity caused by primary varicella in children. Universal vaccination in the United States since 1995 has substantially reduced the incidence of varicella, hospital admissions, and deaths. In Turkey, routine varicella vaccination is being performed since 2013 as a single dose at 12 months of age. Data on severe complications of varicella 
in children in pre-vaccine period is valuable and essential for a comparison between pre- and post-vaccination period to develop immunization recommendation strategies. The aim of the present study is to identify and review varicellarelated hospitalizations, admissions, and complications of primary varicella infection among immunocompetent and immunocompromised children of a large unselected local population in an institution in pre-vaccine period, in Ankara, Turkey.

\section{Materials and Methods}

This study was conducted as a retrospective cohort study at a tertiary care reference center for children with a total number of 270.000 clinic patients per year. Data from children hospitalized with a diagnosis of varicella between January 2004 and December 2010 were analyzed for clinical features, immune status, microbiological findings, varicella complications, management, and outcome.

VZV infections were diagnosed based on typical skin findings, including generalized papullar and vesicular rashes at different stages. The children were included in the study if VZV infection required hospitalization, whether for a varicellarelated complication or for immunosuppression. They were classified into two groups as immunocompromised and immunocompetent. An immune compromising condition was defined as any congenital or acquired immunodeficiency, malignancy, receipt of high dose corticosteroids or chemotherapy within 30 days before the onset of varicella, and severe malnutrition. The term varicella-related complication was applied to all varicella associated events and classified into five groups; secondary bacterial infections, VZV pneumonia, neurological, hematological and other (hepatitis, pancreatitis, stomatitis, disseminated varicella infection). The diagnosis of bacterial superinfection was established by clinical/laboratory findings or was confirmed by bacterial cultures. VZV pneumonia was defined as fever, dyspnea, cyanosis, chest pain and radiographic findings occurring within 2-6 days of the onset of varicella. Neurological complications were diagnosed if fever, altered level of consciousness, ataxia, nuchal rigidity along with consistent cerebrospinal fluid (CSF) or electroencephalogram findings were present. Thrombocytopenia meant a platelet count below 100.000 cells $/ \mathrm{mm}^{3}$ and leukopenia as white blood cell count below 4.000 cells $/ \mathrm{mm}^{3}$. Coagulation disorders were defined as prolonged prothrombin time, activated partial thromboplastin time and consistent variations in d-dimer and fibrinogen levels. Hepatitis was defined as the elevation of serum alanine aminotransferase and aspartate aminotransferase levels to at least twice the normal amount. Disseminated varicella meant laboratory and clinical findings representing infectious involvement in at least two parenchymal organs. Pancreatitis was established by elevated amylase levels, clinical and ultrasonography findings. Stomatitis was defined as painful flat-based ulcers in oral mucosa that cause difficulty in eating. Newborns and children older than 12 years were accepted as high-risk groups for severe VZV infection $(1,4)$.
University of Health Sciences, Ankara Keçiören Training and Research Hospital Ethical Committee (approval number: 1300). In this study, data were obtained from file records, and consent was not obtained due to the retrospective nature of the study.

\section{Statistical Analysis}

Statistical analysis was performed via SPSS 16.0 program. Collected data was presented as the average and standard deviation for symmetrically distributed data and as the mean value for non-symmetrical data. Categorical data (sex, complication, etc.) were presented as incidence. Differences were considered significant at a value of $p<0.05$.

\section{Results}

Between January 2004 and December 2010, 1000 children were referred to the hospital with the diagnosis of varicella and 100 were hospitalized. Of those, 66 were previously healthy, 34 had chronic illnesses leading to immunosuppression. Of the 34 patients, 21 were hospitalized for antiviral therapy despite the absence of complications. All of the immunocompetent patients were hospitalized for complications. None of the children had been previously immunized against varicella. Demographic characteristics and length of hospital stay are summarized in Table I.

\section{Immunocompetent Patients}

In 66 patients there were 85 complications, with fourteen patients $(21 \%)$ having multiple complications. Distribution of the complications is summarized in Table II. Among secondary bacterial infections, the most common complication was skin/ soft tissue infection. Soft tissue infections were mainly seen as invasive bacterial infections (18 patients). Staphylococcus aureus (S. aureus) was isolated from superficial infection

\begin{tabular}{|c|c|c|c|}
\hline & $\begin{array}{l}\text { Immunocompetent } \\
\text { patients }\end{array}$ & $\begin{array}{l}\text { Immunocompromised } \\
\text { patients }\end{array}$ & Total \\
\hline $\begin{array}{l}\text { Number of } \\
\text { patients }\end{array}$ & 66 & 34 & 100 \\
\hline Gender (F/M) & $26 / 40$ & $16 / 18$ & \\
\hline \multicolumn{4}{|l|}{ Age groups } \\
\hline $0-1$ years & 27 & 4 & 31 \\
\hline 1-4 years & 22 & 12 & 34 \\
\hline 4-9 years & 12 & 13 & 25 \\
\hline $9-12$ years & 3 & 3 & 6 \\
\hline$>12$ years & 2 & 2 & 4 \\
\hline $\begin{array}{l}\text { Mean } \\
\text { duration } \\
\text { of hospital } \\
\text { stay (days) }\end{array}$ & $\begin{array}{l}7.7 \\
\text { (median: 7) }\end{array}$ & $\begin{array}{l}6.6 \\
\text { (median: 7) }\end{array}$ & $\begin{array}{l}7.3 \\
\text { (median: 7) }\end{array}$ \\
\hline
\end{tabular}

F: Female, M: Male 
sites in two separate patients with cellulitis and skin abscess. Group A beta-hemolytic streptococcus (GABHS) was isolated in pus culture in one patient with skin abscess, and in a single case of necrotizing fasciitis. Secondary bacterial pneumonia was the second complication in the secondary bacterial infection group; viridans streptococci and coagulase-negative staphylococcus were the isolated pathogens. Hospitalization due to secondary bacterial infection was most common in the 0-1 age group (24 patients). The second largest group covered neurological complications. Acute cerebellar ataxia was the most common complication followed by cerebellitis.
Abnormal electroencephalogram with diffuse slowing was found in one patient with encephalitis. Ten patients underwent CSF examinations and 2 had increased cell counts with normal protein and glucose levels. No pathogens were isolated from CSF examination cultures in any of the cases. All patients with neurological complications were discharged without major sequelae. Reye syndrome was not reported. Neurological complications mostly affected the 1-4 age group (7 patients). VZV pneumonia was diagnosed in 2 patients, one was seven months old and the other was 11 years old. Neither of them had any risk factors for severe VZV

Table II. Type and frequency of complications and laboratory values in the immunocompetent and immunocompromized groups

\begin{tabular}{|c|c|c|c|c|c|c|c|c|c|c|c|c|}
\hline \multirow[b]{3}{*}{ Complications } & \multicolumn{6}{|c|}{ Immunocompetent patients } & \multicolumn{6}{|c|}{ Immunocompromised patients } \\
\hline & \multirow[b]{2}{*}{ n (\%) } & \multirow[b]{2}{*}{$\begin{array}{l}\text { Age (mean) } \\
\text { (years) }\end{array}$} & \multicolumn{4}{|c|}{ Mean } & \multirow[t]{2}{*}{ n (\%) } & \multirow[b]{2}{*}{$\begin{array}{l}\text { Age (mean) } \\
\text { (years) }\end{array}$} & \multicolumn{4}{|c|}{ Mean } \\
\hline & & & $\begin{array}{l}\text { Duration of } \\
\text { hospital stay } \\
\text { (days) }\end{array}$ & $\begin{array}{l}\text { WBC } \\
(1000 \\
\text { cells/ } \\
\left.\mathrm{mm}^{3}\right)\end{array}$ & $\begin{array}{l}\text { CRP } \\
(\mathrm{mg} / \\
\mathrm{dL})\end{array}$ & $\begin{array}{l}\text { ESR } \\
(\mathrm{mm} / \\
\mathrm{hr})\end{array}$ & & & $\begin{array}{l}\text { Duration } \\
\text { of hospital } \\
\text { stay (days) }\end{array}$ & $\begin{array}{l}\text { WBC } \\
(1000 \\
\text { cells } \\
\left./ \mathrm{mm}^{3}\right)\end{array}$ & $\begin{array}{l}\text { CRP } \\
(\mathrm{mg} / \\
\mathrm{dL})\end{array}$ & $\begin{array}{l}\text { ESR } \\
(\mathrm{mm} / \\
\mathrm{hr})\end{array}$ \\
\hline $\begin{array}{l}\text { Secondary bacterial } \\
\text { infection }\end{array}$ & $46(54)$ & 2.4 (median: 1.2) & 8.1 (median: 6.5 ) & 11.1 & 67.4 & 48.3 & $8(50)$ & 4.6 (median: 3) & & & & \\
\hline Cellulitis & 18 & & & & & & 3 & & & & & \\
\hline Pneumonia & 16 & & & & & & 4 & & & & & \\
\hline Skin abcess & 3 & & & & & & - & & & & & \\
\hline Preceptal cellulitis & 3 & & & & & & - & & & & & \\
\hline Impetigo & 3 & & & & & & 1 & & & & & \\
\hline Arthritis & 1 & & & & & & - & & & & & \\
\hline Conjunctivitis & 1 & & & & & & - & & & & & \\
\hline Necrotizing fasciitis & 1 & & & & & & - & & & & & \\
\hline VZV pneumonia & $2(3)$ & 5.8 & 12 & 12 & 190 & 56 & 0 & - & - & - & - & - \\
\hline $\begin{array}{l}\text { Neurological } \\
\text { complications }\end{array}$ & $18(21)$ & 4.9 (median: 3.5 ) & 7.6 (median: 7) & 9.8 & 17.3 & 47.4 & 0 & - & - & - & - & - \\
\hline Ataxia & 5 & & & & & & - & & & & & \\
\hline Cerebellitis & 4 & & & & & & - & & & & & \\
\hline Febrile seizures & 3 & & & & & & - & & & & & \\
\hline Encephalitis & 3 & & & & & & - & & & & & \\
\hline Meningitis & 2 & & & & & & - & & & & & \\
\hline Facial paralysis & 1 & & & & & & - & & & & & \\
\hline $\begin{array}{l}\text { Haematological } \\
\text { complications }\end{array}$ & $4(5)$ & 5.5 (median: 5) & 9.8 (median: 7.5) & 9.1 & 98.7 & 41.7 & $1(6)$ & 12 & 2 & 6.4 & 10 & 8 \\
\hline Thrombocytopenia & 2 & & & & & & - & & & & & \\
\hline Granulocytopenia & 1 & & & & & & - & & & & & \\
\hline DIC & 1 & & & & & & 1 & & & & & \\
\hline Other complications & $15(18)$ & 2.8 (median: 0.6) & 8.3 (median: 6) & 8.8 & 64.6 & 39 & 7 (44) & 6.2 (median: 7) & 6.1 (median: 6) & 18.2 & 14.1 & 19.1 \\
\hline Hepatitis & 10 & & & & & & 6 & & & & & \\
\hline $\begin{array}{l}\text { Disseminated } \\
\text { varicella infection }\end{array}$ & 2 & & & & & & 1 & & & & & \\
\hline Stomatitis & 2 & & & & & & - & & & & & \\
\hline Pancreatitis & 1 & & & & & & - & & & & & \\
\hline
\end{tabular}

N: Number, DIC: Disseminated intravascular coagulation, WBC: White blood cell, CRP: C-reactive protein, ESR: Eritrocyte sedimentation rate, VZV: Varicella-zoster virus 
infection. No pathogens were isolated from blood cultures in either of the patients. Hematological complications were seen in 4 patients. Of these, 2 had thrombocytopenia, 1 had granulocytopenia and 1 had disseminated intravascular coagulation (DIC). Two of them were in the 0-1 age group, and the other 2 were in the 9-12 age group. One of the patients that developed thrombocytopenia was a 10 -yearsold male patient, admitted to the physician for epistaxis and skin bruising. In the complete blood count, platelet number was 2000 cells $/ \mathrm{mm}^{3}$ and in the bone marrow aspiration, increased number of megakaryocytes were seen, suggesting the diagnosis of immune thrombocytopenic purpura (ITP). Disseminated varicella was seen in 2 female patients aged 7 months and 11 years, and neither of them had risk factors for a severe disease. Overall, 38 of the patients (58\%) received antibiotics and acyclovir, $17(26 \%)$ received only antibiotics, $9(14 \%)$ only acyclovir, and $2(3 \%)$ received neither of these. Two patients received intravenous immunoglobulin (IVIG), one with disseminated varicella and necrotizing fasciitis, and the other with ITP. The patient with necrotizing fasciitis required surgical intervention for debridement. This patient with dermal scarring was the only patient who had sequelae attributable to varicella complications. The only fatal outcome was a 2-months-old patient who had experienced household exposure to varicella three weeks before the appearance of the rash. She was admitted to the hospital on the $10^{\text {th }}$ day of the rash with fever, feeding difficulty and tachypnea. Diffuse pulmonary infiltrations were detected in the chest $X$-ray. Despite the intravenous antiviral and antibacterial therapy, she died due to respiratory failure on the fourth day of hospitalization.

\section{Immunocompromised Patients}

Patients in the immunocompromised group, with or without complications, were hospitalized for antiviral therapy and observation. Immune-compromising conditions were chemotherapy within 30 days before the onset of varicella in 27 patients, high-dose corticosteroid therapy within 30 days in 4 patients (two with Nephrotic syndrome, one with membranoproliferative glomerulonephritis, one with acute rheumatic fever (ARF), and congenital immunodeficiency in two patients (one with Whim syndrome, one with common variable immunodeficiency), and severe malnutrition in one patient. In 34 patients there were 16 complications, and two of them had more than one complication. Distribution of the complications is summarized in Table II. Among the patients with multiple complications, one had cellulitis and hepatitis, and the other had DIC, hepatitis, and disseminated varicella. Overall, $18(53 \%)$ of the patients received only acyclovir, 16 $(46 \%)$ received both antibiotics and acyclovir. Two patients with congenital immunodeficiency received IVIG. Both of the patients had been receiving regular IVIG before the VZV infection. Neither of the patients required surgical intervention. Major sequelae were not recorded. The only fatal outcome was a 12 year-old-female who was receiving high dose steroids for ARF. She was admitted to the hospital two days after the onset of rash with generalized hemorrhagic vesicles, hematuria, and arthralgia. She developed thrombocytopenia, DIC, and fulminant hepatic failure on the third day of hospitalization and died due to disseminated varicella despite aggressive therapy.

\section{Discussion}

Although varicella is known as a benign disease of childhood, hospitalization rates have been reported to be $2-3 / 1000$ among children (2). In Turkey, it is anticipated that $90 \%$ of the children will be exposed to the disease until the age of 15 and the estimated hospitalization rate in the prevaccine period was reported to be 5.29-6.89/100.000 (5). Our study was conducted at a tertiary care center with a number of 270.000 clinic patients per year, and among 1000 varicella related admissions, 100 varicella-related hospitalizations were determined. We found that $10 \%$ of the varicella-related admissions ended up being hospitalized. The high hospitalization rate in our study could be attributed to the fact that our study was conducted in a tertiary center to which complicated and severe cases are referred.

Varicella has the highest incidence in children aged 1-9 years. The highest hospitalization rates are reported during the first year of life, which has also been observed in the immunocompetent group in our study $(1,4,5)$. Populationwide vaccination and herd immunity is the only realistic option for the prevention of the disease in children under 1 year old. The distribution of the complications was consistent with previous studies (6-9). Secondary bacterial infections caused by particularly GABHS and $S$. aureus are the most common complications $(1,3,7)$. Consistently in our study, secondary bacterial infections were most common; $S$. aureus being isolated in 2 separate patients with cellulitis and skin abscess; GABHS in 2 separate patients with skin abscess and necrotizing fasciitis. Neurological complications, which are very worrisome for caregivers, are second in order of frequency among varicella-associated complications, especially in previously healthy children younger than 5 years of age $(1,3,6-9)$. VZV pneumonia is a well-recognized serious complication of varicella, especially in immunocompromised children, adults and newborns. However, it is rare among previously healthy children. In our study, although neurological complications were also seen second in order of frequency, and mostly affected the 1-4 age group among the immunocompetents, they were not seen in the immunocompromised group. Like neurological complications, VZV pneumonia was not detected in the immunocompromised group. These findings may be related to the small study population but can also be explained by the heightened risk awareness of the caregivers of these patients, and the early initiation of antiviral treatments. In our study, VZV pneumonia was seen in $2(3 \%)$ patients in the immunocompetent group and neither of them had any of the risk factors. 
Thrombocytopenia, DIC and purpura fulminans are the well-known hematological complications of varicella although they are rare in childhood $(3,7,9)$. In our study hematological complication rate was found as $5 \%$ in the immunocompetent group and $6 \%$ in the immunocompromised group consistent with previous studies $(3,7,10)$. Factor $V$ Leiden, protein $\mathrm{C}$ and $\mathrm{S}$ deficiencies were suggested as risk factors for DIC in VZV infection $(11,12)$. However, in our study it was not possible to make an interpretation because such hypercoagulability factors were not studied in patients with DIC. Varicella-related ITP was reported in studies from Sweden and Israel only in two previously healthy children $(5,13)$. This rare complication was also seen in our study in the immunocompetent group with a recovery period of six months. Varicella appears to cause transient hepatitis in children with a rate of $3-3.5 \%(3,7,14)$. In our study the overall hepatitis rate was $16 \%$ with $6(9 \%)$ patients in the immunocompetent and 10 (29\%) in the immunocompromised group. None of the patients developed hepatic failure except one patient with disseminated varicella infection. The high rate of hepatitis in the immunocompromised group may have been due to the manifestations of the underlying disease. Myocarditis, pericarditis, pancreatitis, renal complications, and Reye syndrome are very rare complications of varicella. In our cohort, there was only one case of pancreatitis. Reye syndrome was not observed, possibly owing to the withholding of salicylates from children since the 1990's. Disseminated varicella is a severe complication of varicella with visceral organ involvement, severe hemorrhage, and coagulopathy. Although adolescents, adults, pregnant women, newborns, immunocompromised children are at increased risk of disseminated varicella, previously healthy children may also be affected with high morbidity and mortality rates. In studies from Turkey and Sweden disseminated varicella was seen in $3 \%$ of previously healthy children, which is consistent with our study, suggesting that varicella may also be severe in previously healthy children $(6,8)$. In our study, the median hospital stay length was 7 days similar to previous studies in other countries which reported median hospital stay as ranging from 4 to 7 days $(6,7)$. Only one patient had longterm sequelae, attributed to necrotizing fasciitis in previously healthy children, consistent with a study from Germany which reported the sequelae rate as $1.7 \%$ (15). Two patients $(2 \%)$ died, one of secondary bacterial pneumonia and the other of disseminated varicella. In studies from Ireland and England, the death rate was found as $3.1 \%$ and the high rate was attributed to the involvement of only severe cases in that study (16). In other studies from Sweden and Germany, no fatality was reported $(9,10)$. Although varicella usually results in mild to moderate illness in immunocompetent patients, serious complications can arise (1). Most of the varicella-related complications were reported in children without severe underlying immune compromising conditions $(14,17,18)$. Our study suggests that in previously healthy children, severe complications requiring hospitalization are more than in the immunocompromised children due to the increased risk awareness and early initiation of antiviral treatment in these children.

\section{Study Limitations}

This study was conducted in a small group of patients in a single center thus has limitations for generalisation of the data.

\section{Conclusion}

In conclusion, since varicella virus vaccine prevents most of the morbidity and mortality caused by primary varicella in children, prevention rather than the treatment has therefore been recommended as the optimal approach $(2,19,20)$. Universal vaccination appears to be the best way to reduce the incidence of varicella, and achieving this will also protect those who are not eligible for vaccination such as immunocompromised individuals and infants $(19,21)$. Despite the common perception of varicella infection being harmless, complications requiring hospitalization are frequent, potentially serious, and costly even in healthy children. All of the immunocompetent patients in the study group, who needed hospitalization for varicella-related complications had serious medical conditions. Universal varicella immunization that was launched in 2013 may reduce this high rate of varicella-related complications and hospital admissions in our country. The surveillance of varicella-associated complications is essential for monitoring the impact of varicella immunization. Our study provides data to compare hospitalization indications and varicella complications in immunocompromised and immunocompetent children.

\section{Ethics}

Ethics Committee Approval: This study was approved by the University of Health Sciences, Ankara Keçiören Training and Research Hospital Ethical Committee (approval number: 1300).

Informed Consent: In this study, data were obtained from file records, and consent was not obtained due to the retrospective nature of the study.

Peer-review: External and internal peer-reviewed.

\section{Authorship Contributions}

Surgical and Medical Practices: N.G.T., Ö.A.D., S.T.O., Concept: N.G.T., Ö.A.D., Design: N.G.T., Ö.A.D., Data Collection or Processing: Ö.A.D., S.T.O., Analysis or Interpretation: N.G.T., Ö.A.D., Literature Search: Ö.A.D., S.T.O., Writing: Ö.A.D.

Conflict of Interest: No conflict of interest was declared by the authors.

Financial Disclosure: The authors declared that this study received no financial support.

\section{References}

1. Heininger U, Seward JF. Varicella. Lancet 2006;368:1365-76.

2. The Pink Book. Epidemiology and Prevention of VaccinePreventable Diseases. 13th ed. Course Textbook, 2015. p. 353-76. 
3. Arvin AM. Varicella-zoster virus: molecular virology and virus-host interactions. Curr Opin Microbiol 2001;4:442-9.

4. Gershon AA. Varicella zoster virus In: Feigin RD, Cherry JD (eds). Textbook of Pediatric Infectious Diseases 4th ed. Philadelphia WB Saunders, 1998;1769-77.

5. Dinleyici EC, Kurugol Z, Turel O, et al. The epidemiology and economic impact of varicella-related hospitalizations in Turkey from 2008 to 2010: a nationwide survey during the pre-vaccine era (VARICOMP study). Eur J Pediatr 2012;171:817-25.

6. Jaeggi A, Zurbruegg RP, Aebi C. Complications of varicella in a defined central European population. Arch Dis Child 1998;79:472-7.

7. Peterson CL, Mascola L, Chao SM, et. al. Children hospitalized for varicella: a pre-vaccine review. J Pediatr 1996;129:529-36.

8. Koturoglu G, Kurugöl Z, Cetin N et al. Complications of varicella in healthy children in Izmir, Turkey. Pediatr Int 2005;47:296-9.

9. Theodoridou M, Laina I, Hadjichristodoulou C, Syriopoulou V. Varicella related complications and hospitalizations in tertiary pediatric medical centre before vaccine introduction. Eur $J$ Pediatr 2006;165:273-4.

10. Ziebold C, von Kries R, Lang R, Weigl J, Schmitt HJ. Severe complications of varicella in previously healthy children in Germany: a 1- year survey. Pediatrics 2001;108:79.

11. Woods CR, Johnson CA. Varicella purpura fulminans associated with heterozygosity for factor $V$ Leiden and transient protein C deficiency. Pediatrics 1998;102:1208-10.

12. Busuttil DP, Hay CR, Lewis MA, Wynn RF. Aggressive multiple modality therapy for varicella-associated purpura fulminans. Br J Hematol 2000;110:1012-3.
13. Amir A, Gilad O, Yacobovich J, Scheuerman O, Tamary $H$, Garty BZ. Post-varicella thrombocytopenic purpura. Acta Pediatr 2010;99:1385-8.

14. Bonhoeffer J, Baer G, Muehleisen B, et al. Prospective surveillance of hospitalizations associated with varicellazoster virus infections in children and adolescents. Eur $\mathrm{J}$ Pediatr 2005;164:366-70.

15. Liese JG, Grote V, Rosenfeld E, Fischer R, Belohradsky BH, $\checkmark$ Kries $R$, et al. The burden of varicella complications before the introduction of routine varicella vaccination in Germany. Pediatr Infect Dis J 2008;27:119-24.

16. Nguyen $\mathrm{H}$, Jumaan $\mathrm{AO}$, Seward JF. Decline in mortality due to varicella after implementation of varicella vaccination in the United States. N Engl J Med 2005;352:450-8.

17. Cameron JC, Allan G, Johnston F, Finn A, Heath PT, Booy R. Severe complications of chickenpox in hospitalised children in the UK and Ireland. Arch Dis Child 2007;92:1062-6.

18. Galil K, Brown C, Lin F, Seward J. Hospitalizations for varicella in the United States, 1988 to 1999. Pediatr Infect Dis J 2002;21:931-5.

19. Rentier B, Gershon AA; European Working Group on Varicella. Consensus: Varicella vaccination of healthy children-a challenge for Europe. Pediatr Infect Dis J 2004;23:379-89.

20. American Academy of Pediatrics Committee on Infectious Diseases. Recommended childhood and adolescent immunization schedule: United States, July-December 2004. Pediatrics 2004;113:1448.

21. Vázquez M, LaRussa PS, Gershon AA, et al. Effectiveness over time of varicella vaccine. JAMA 2004;291:851-5. 